past, and that it seems determined to follow in the future.

The Association, by its rejection of the trade union amendment, has marked out the path along which the Guild will travel. We shall go on and go forward, securing adherents where we can, and steadily raising and setting on one side a defence fund for the use of our members; a fund which shall be free from the enormous administration charges proposed by the State Sickness Insurance Committee, and free also from the attacks of the enemy when next it becomes necessary to fight. Further, we appeal to all those gentlemen and their constituents who voted for the amendment to come over and help us, in order that we may have that strength that numbers alone can give.

\title{
Guild Notes.
}

The opening of the Guild offices at 13 old Steine was a conspicuous success, and every day found numerous enquirers who were anxious and willing to learn what the new movement stood for and what it hoped to do. At the time of going to press the meeting is not yet over, and it is impossible to say what the net result is to the Guild in new members, but we have the satisfaction of knowing that we have sown the seed which will be carried to all parts of the country, and we trust will bear fruit later on when the member has had time and leisure to digest the objects and aims of the Guild.

According to Dr. Wallace Henry, neither the Leicester Union nor the National Medical Guild can claim to be the first medical trade union. In an interesting and instructive speech he reminded the representatives that William III. granted a charter to the Guild of St. Luke in certain parts of Ireland, and that they were given powers to regulate the rates and charges of their members. Possibly the medical men of William III.'s time were not " gentlemen by Act of Parliament."

In the autumn it will be necessary for the National Medical Guild to take a ballot of its members on the subject of incorporating the "political objects" provision of the new Trade Union Act. The Guild proposes to wait until the autumn, as so many of its members are now taking a well-earned rest and do not desire to be worried with matters medical whilst away on a holiday. At present the powers of the Guild do not permit it to use any portion of its funds in the advancement of any political object, and the Council propose to ask the opinion of the members on the subject.

One result of the Brighton meeting was the formation of still another non-panel body, the co-ordinating centre of which is to be London. Dr. E. B. Turner, we believe, is the president, and Dr. Chas. Buttar the chairman. In the multiplicity of counsellors there may be wisdom, but in the multiplicity of organisations we fear there is disaster, and we hope that in the near future they will all come to see that the course mapped out by this body is sufficiently generous to include the non-panel men as well as the panel. Whilst on this subject we may say that the Guild feels a little sore at the attitude of the non-panel doctors towards it, and we should like to remind them that the first action that the Guild fought and won was solely in their interests (we refer to Heard $v$. Pickthorne). That action was a very difficult and expensive one, and the result should have commanded the confidence of the non-panel doctors. One is almost tempted to say, "Ingratitude thy name is non" panel.'

\section{Fast Suffolk and Ipswich Hospital.}

THIS institution held its seventy-seventh annual meeting at the Town Hall, Ipswich, on July 19; the veteran President, Dr. J. H. Bartlet, presided. The report from the board of management contained some references of more than passing interest. The annual subscriptions received were in excess of any previous year, while the Employés' Organisation only fell short of the record by £59. During the year a new dental department was installed, and an addition was made to the out-patient department, including rooms for $x$-ray work, electric baths, a casualty theatre, and surgeries. The difficulty of finding residents resulted in the appointment of a lady doctor to the vacant post of house physician. The increased price of all commodities, coupled with an increase in the number of in-patients, advanced the ordinary expenditure to such an extent that a deficit of $£ 575$ accrued on the year's working. The board pointed to the mecessity for balconies to the main wards and for a convalescent home in connection with the hospital, but await the beneficence of individuals rather than sell securities at the present moment. The salary of the secretary, Mr. A. Griffiths, was increased, and a cheque was awarded to him as an honorarium for special services. During the three and a half years that Mr. Griffiths has held the appointment at Ipswich he has changed the system of accounts of that institution to that of the Uniform System. $\mathrm{He}$ has also written some articles on hospital accountancy which have appeared in this Journal. It is not always that capable officers obtain recognition in so tangible a form, and we congratulate Mr. Griffiths.

\section{LEWIS'S POCKET CASE-BOOK.}

$\mathrm{W}_{\mathrm{E}}$ have received from $\mathrm{Mr}$. H. K. Lewis a new Pocket Case-Book designed for the use of students and practitioners. The book is neatly bound in limp cloth, and the page measures $8 \mathrm{in}$. by $5 \mathrm{in}$. It is arranged for twenty-five cases; four pages are allotted to each case, and the headings are arranged for the record of the usual particulars, including personal history, family history, and present condition. The space allotted to the family history is, we think, unnecessarily large compared with that available for personal history. Otherwise the arrangement of the whole case-book is admirable. There are also diagrams for the marking of physical signs, space for diagnosis, prognosis, and extra space for the record of treatment and progress, including a miniature temperature chart which should be very useful. The price is 1 s. $6 \mathrm{~d}$. net. 